\title{
RELATION OF MEDIAN NERVE WITH BRACHIAL ARTERY: A CADAVERIC STUDY
}

\author{
Eti Sthapak, Navbir Pasricha, Rajan Bhatnagar \\ Department of Anatomy, Dr. Ram Manohar Lohia Institute of Medical Sciences, Lucknow, UP, India
}

\begin{abstract}
Introduction: Variation in neurovascular structure are commonly encountered in routine dissection. Brachial artery is the main artery of upper limb. In the arm, the median nerve passes at first lateral to brachial artery (near the insertion of coracobrachialis muscle), then crosses in front of the artery, descending medial to it in the cubital fossa. The knowledge of these variation could be helpful to vascular, plastic, general surgeons and orthopedicians. It is also important to prevent iatrogenic injuries. The aim of this study was to evaluate anatomical variations in course and relation of median nerve to brachial artery in the arm.

Material \& Methods: The study was conducted in 50 cadavers (100 upper limbs) in duration of two years. Proper cadaveric dissection was done in the Department of Anatomy, Dr. RML Institute of Medical Sciences, Lucknow, and Era's Lucknow Medical College, Lucknow.

Observation \& Results: In the present series, median nerve was found to cross behind the brachial artery at about the middle of the arm in $8 \%$ cadavers. Median nerve entered the arm at first lateral to brachial artery, near the insertion of coracobrachialis. In 46 cadavers (96 upper limbs), it crossed in front of the artery from lateral to medial side. In four cadavers ( 5 upper limbs), it passed posterior to the brachial artery in the arm.

Conclusion: Knowledge of the brachial artery and their variations are of clinical and surgical importance. An awareness of such a presence is valuable for the surgeons and radiologists in evaluation of angiographic images, vascular and re-constructive surgery or appropriate treatment for compressive neuropathies.
\end{abstract}

Keywords: Brachial artery, median nerve, variations

\section{INTRODUCTION}

Alteration from usual course of nerve and vessels of upper limb is not uncommon finding, but it has important clinical implications. The knowledge of these variation could be helpful to vascular, plastic, general surgeons, orthopedicians and to prevent iatrogenic injuries.

The median nerve has two roots from the lateral cord $(\mathrm{C} 5,6,7)$ and medial cord (C8 \& T1), which embrace the third part of axillary artery and unite anterior or lateral to it. Median nerve enters the arm at first lateral to brachial artery, near the insertion of coracobrachialis it crosses in front of the artery descending medial to it in the cubital fossa without receiving any branch. It supplies most of the flexor muscles in the anterior aspect of the forearm along with muscles of thenar eminence and lateral two lumbricals [1].

Unusual course of median nerve may mislead and cause confusion in identifying it for repairing damaged median nerve and/or cause complications in other iatrogenic activities $[2,3]$.

The brachial artery, a continuation of the axillary artery, begins at the distal (inferior) border of the

Address for Correspondence:

Dr. Navbir Pasricha, Department of Anatomy, Dr. Ram Manohar Lohia Institute of Medical Sciences, Lucknow, UP, India | Mob: 8953671222 Email- nivibedi@gmail.com 
tendon of teres major and ends about a centimetre distal to the elbow joint (at the level of the neck of the radius) by dividing into radial and ulnar arteries. At first it is medial to the humerus, but gradually spirals anterior to it until it lies midway between the humeral epicondyles. Its pulsation can be felt throughout.

The brachial artery is wholly superficial, covered anteriorly only by skin, superficial and deep fasciae. At the elbow the brachial artery sinks deeply into the triangular intermuscular cubital fossa. Artery shows wide range of variations in upper limb [4]. Accessory brachial artery was first established by Mc Cormack and embryologically it referred to as the superficial brachial artery [5]. Variations in the incidence of superficial brachial artery $(0.66-1.25 \%)$ have been reported in literature [6]. Injuries of the upper limb either due to accident or surgeries or even routine procedures such as intravenous cannulation can lead to damage to these vessels. Large size superficially lying arteries provide large size pedicles for local reconstructive surgeries in the shoulder, arm and elbow region. Thus prior knowledge of such variations may be quite useful [6].

This study was done to evaluate anatomical variations in the course and relation of median nerve to brachial artery in the arm.

\section{MATERIAL AND METHODS}

The study was conducted in 50 cadavers (100 upper limbs) in duration of two years. Proper cadaveric dissection was done in the Department of Anatomy, Dr. RML Institute of Medical Sciences, Lucknow, and Era's Lucknow Medical College, Lucknow.

The arm and cubital fossa were dissected to expose brachial artery and median nerve as per Cunningham's manual [7]. The normal anatomy and variations in relation of median nerve to brachial artery was observed and photographs of the variant upper limbs were taken.

Results were compared with normal standard course and relation of median nerve with brachial artery as stated in Gray's Anatomy [1\}. Distance of formation of median nerve from bony landmark namely coracoid process (proximally) was meticulously measured.

Variations were calculated in percentage with reference to total number of observations. Analysis was done by using SPAPA 11.1 version and data was presented in mean \pm SD (standard deviation), frequency, percentage. In the case of categorical data, Chi square test was used. $\mathrm{P}$ value $<.05$ was taken as statistically significant.

\section{OBSERVATIONS AND RESULTS}

Median nerve and brachial artery were studied with regards to relation of median nerve at its formation with axillary artery, distance from coracoid process to formation of median nerve, and relation of median nerve to brachial artery in the arm.

\section{Relation of median nerve at its formation with axillary artery}

Formation of median nerve was seen anterior and anterolateral in 92 upper limbs and medial in 8 upper limbs in relation to third part of axillary artery (5-Right upper limbs, 3- Left upper limbs).

\section{Distance from coracoid process to formation of median nerve}

We observed that median nerve was formed in upper third of the arm at variable distance. The mean distance from the coracoid process to formation of median nerve by two roots was $4.4 \pm 1.16$ (varied from 2.5 to 8$) \mathrm{cm}$ on right side whereas it was $4.3 \pm 1.44$ (varied from 2.5 to 9 ) $\mathrm{cm}$ on left side. The mean distance between right and left was not statistically significant ( $p$ value $=0.94$ ). High and low formation of median nerve in the axilla was noted and photographed (Fig. 1a,b \& 2a,b).

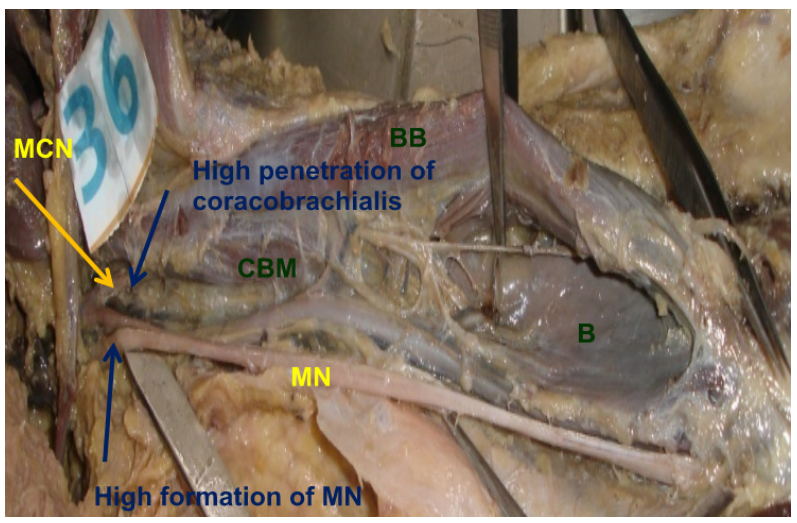

Fig. 1a: Photograph showing high formation of median nerve in left arm (MCN: Musculocutaneous nerve, MN: Median nerve, B: Brachialis, BB: Biceps brachii, CBM: Coracobrachialis) 


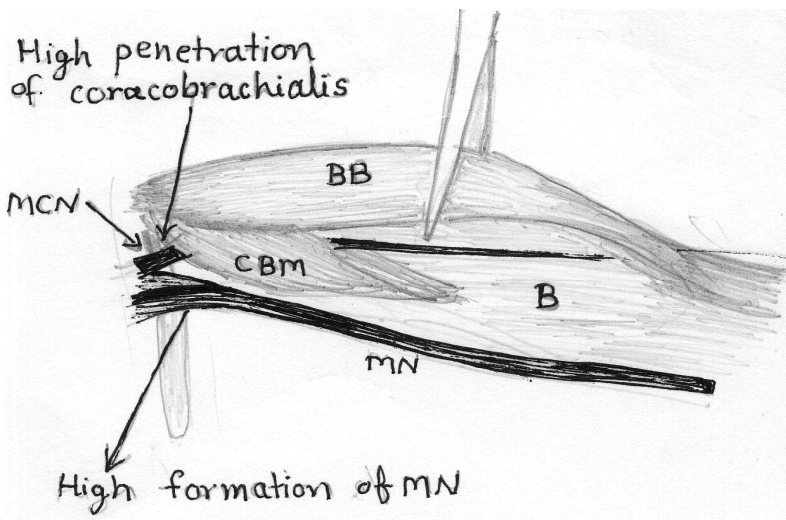

Fig. 1b: Schematic representation of Fig. 1a (MCN: Musculocutaneous nerve, MN: Median nerve, B: Brachialis, BB: Biceps brachii, CBM: Coracobrachialis)

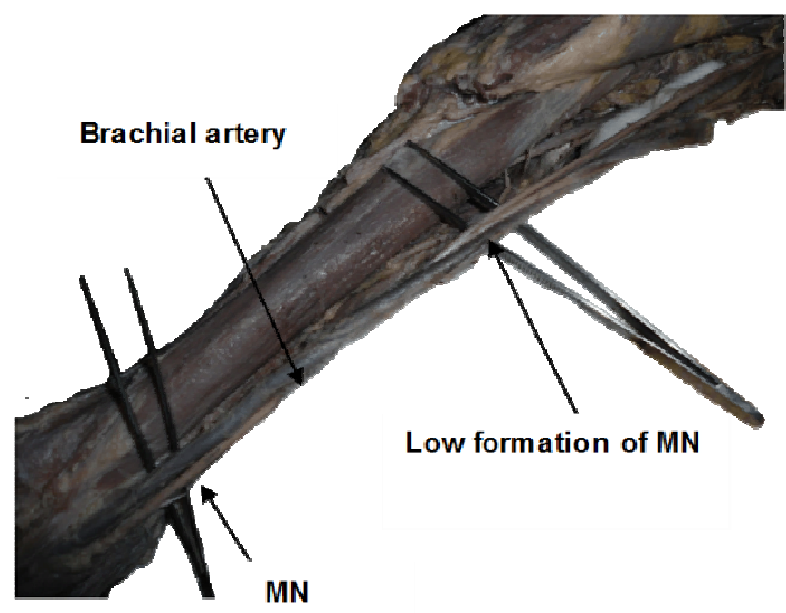

Fig. 2a: Photograph showing median nerve crossing posterior to brachial artery and low formation of median nerve (MN)

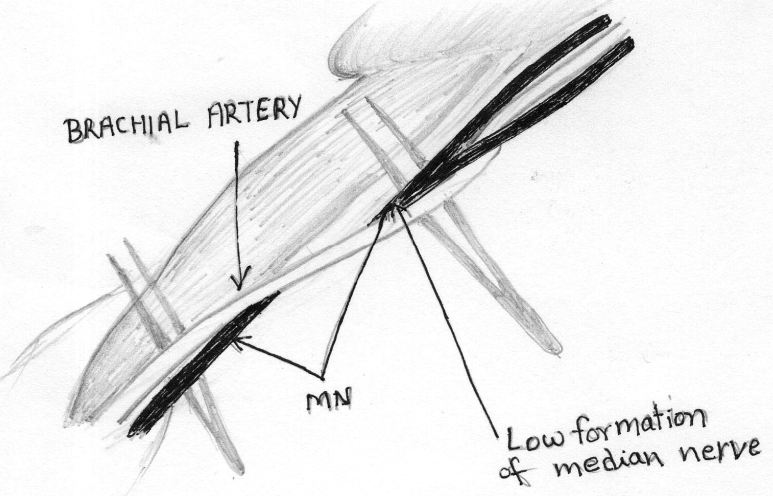

Fig. 2b: Schematic representation of Fig. 2a (MN: Median nerve) Relation of median nerve to brachial artery in the arm
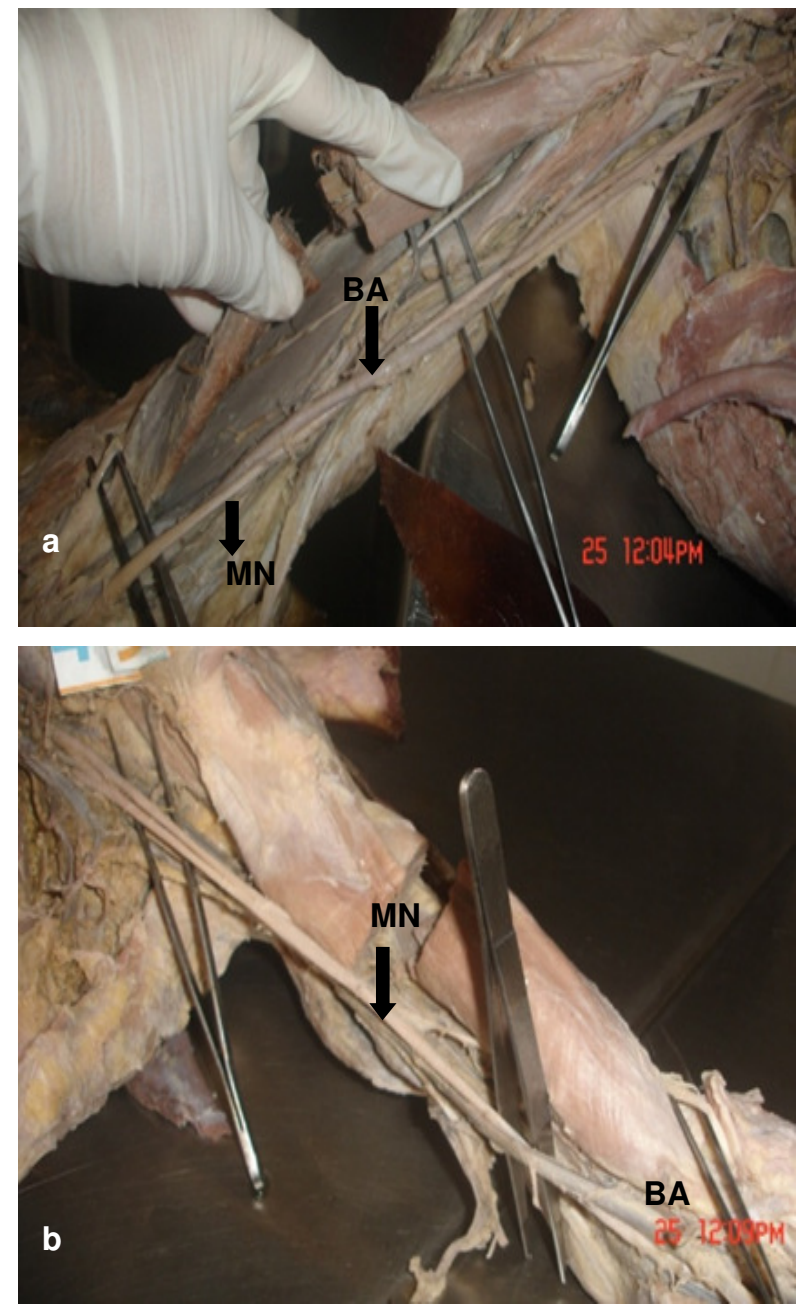

Fig. 3a\&b: Arm showing median nerve crossing deep (posterior) to the brachial artery from lateral to medial side (bilaterally) (MN: Median nerve, BA: Brachial artery)

Median nerve entered the arm at first lateral to brachial artery, near the insertion of coracobrachialis it crossed in front of the artery in 46 cadavers (96 upper limbs) from lateral to medial side. In four cadavers, ( 5 upper limbs) it passed posterior to the brachial artery in the arm (Fig. 3a,b, Table 1).

Table 1: Relation of median nerve with brachial artery in the arm

\begin{tabular}{|c|c|c|}
\hline $\begin{array}{c}\text { Relation of median } \\
\text { nerve with brachial } \\
\text { artery in arm }\end{array}$ & Crossed anteriorly & $\begin{array}{c}\text { Crossed } \\
\text { posteriorly }\end{array}$ \\
\hline No. of cadavers & 46 (96 upper limbs) & 4 (5 upper limbs) \\
\hline Percentage & $92 \%$ & $8 \%$ \\
\hline
\end{tabular}


This variation was observed bilaterally (Fig. 3) in one and unilaterally (Fig. 2) in three cadavers. Thereafter the nerve accompanied the medial side of the artery and appeared in the cubital fossa. Median nerve left the cubital fossa between the two heads of pronator teres and appeared between the superficial and deep groups of flexor muscles of the forearm.

In one right arm, brachial artery divided high in the arm into superficial and deep branches. In this case, median nerve crossed posterior to the superficial branch of brachial artery (SBA) from lateral to medial side. Thereafter the superficial branch continued as radial artery and deep branch followed the course of ulnar artery (Fig. 4a,b).
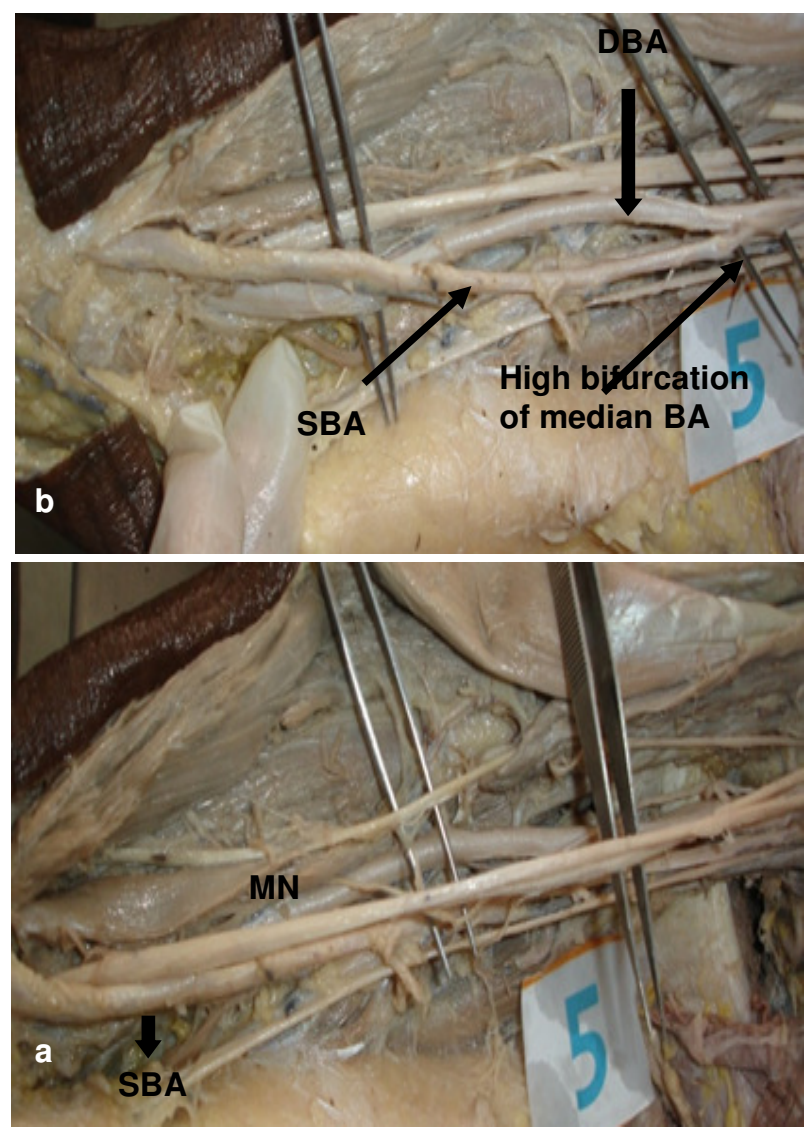

Fig. 4a\&b: Right arm showing high bifurcation of brachial artery \& median nerve crossing lateral to medial side behind the superficial brachial artery in lower segment of arm (MN: Median nerve, SBA: Superficial branch of brachial artery, DBA: Deep branch of brachial artery)

\section{DISCUSSION}

\section{Relation of median nerve at its formation with axillary artery}

Normally formation of median nerve takes place lateral to third part of axillary artery. Haviarova et al. (2009) [8] described a case where median nerve was formed behind the axillary artery though in our series we have not found such variation. Formation of median nerve medial to the axillary artery had been described by various authors [9-11]. In present study, median nerve formed medial to axillary artery in $4(8 \%)$ cadavers which is slightly more than previously reported series. Pandey \& Shukla (2007) observed such variation in $4.7 \%$ cases [12] whereas Bhudiraja et al. (2011) reported $6.12 \%$ cases of his series having such variation [13]. This variation is important in posttraumatic evaluation of peripheral nerves.

\section{Distance from coracoid process to formation of median nerve}

The mean distance from coracoid process to formation of median nerve by two roots was $4.4 \pm 1.16$ (varied from 2.5 to 8$) \mathrm{cm}$ on right side whereas it was $4.3 \pm$ 1.44 (varied from 2.5 to 9 ) $\mathrm{cm}$ on left side. The median nerve is usually formed in the axilla by the union of medial and lateral roots [1]. Our results are comparable to that of Bhudiraja et al. (2011) who reported the incidence of low fusion of two roots in $17 \%$ cases though they have not described the limit for the low fusion of two roots [13]. Testut and Latarjet (cited by Jakubowicz and Ratajczak, 2000) [14] reported that the lateral root united with the medial root as low as at the level of the cubital fossa to form median nerve. Jakubowicz and Ratajczak (2000) [14] reported that the two roots of the median nerve united lower than normal. The clinical importance of such variation lies in surgical procedure and nerve block anaesthesia, because if nerve block is given proximal to the fusion of the roots effect will not be proper.

\section{Relation of median nerve to brachial artery in the arm}

In the present series, median nerve was found to cross posterior to brachial artery at about the middle of the arm in $8 \%$ cadavers (Fig. 2-4). Joshi et al. (2008) reported this variation in $4.7 \%$ of cases [15]. Sudarshan et al. (2013) studied relation of median nerve to brachial artery in 95 upper limbs. He noted that median nerve coursed superficial to artery in $88.42 \%$ (45 right \& 39 left) and deep to the artery i.e. superficial brachial artery was seen in $11.57 \%$ of limbs (6 right \& 5 left) [16]. Bharti et al. (2015) in their study 
on 10 cadavers noted, that in one cadaver median nerve crossed brachial artery in the arm behind instead of coming in front [17]. The brachial artery coursing in front of rather than behind the median nerve is called superficial brachial artery [16].

Most of the earlier reports of superficial brachial artery, by both large sample studies and case reports, are associated with two brachial arteries in the arm where one is superficial and the other is deep to the median nerve. Anomalies of the forelimb arteries are very common. This is because of their multiple and plexiform sources of origin, the temporal succession of emergence of principal arteries, anastomosis and periarterial network and functional dominance followed by regression of some paths [18]. Persistence of embryological vessels may be the basis of SBA. Miller believed that superficial brachial artery is an atavistic condition (retention of a primitive pattern), as the main brachial artery crossing superficial to median nerve is the usual arrangement in the primates [18]. Different studies have reported varied prevalence of superficial brachial artery.

Brachial artery, while crossing over the median nerve, can lay over it for some distance and compress the nerve. The diagnosis of this condition could be confusing because the symptoms resemble radiculopathy or carpal tunnel syndrome [19]. Also in cases of SBA, the superficial position of the artery renders it vulnerable to trauma. However when required, it is easily accessible for cannulation. Also SBA may be mistaken for a vein and accidental intraarterial injection of drugs may result in serious consequences.

\section{CONCLUSION}

Knowledge of the median nerve, brachial artery and their variations are of clinical and surgical importance. An awareness of such a presence is valuable for the surgeons and radiologists in evaluation of angiographic images, vascular and re-constructive surgery or appropriate treatment for compressive neuropathies.

\section{REFERENCES}

1. Standring S. Gray's Anatomy. The Anatomical Basis of Clinical Practice. $40^{\text {th }}$ ed., London, Churchill Livingstone Elsevier. 2008; pp. 821-822.

2. Singh $R$ and Wadhwan $M$. Unusual course of median nerve in arm and forearm. Int J Anat Var. 2016; 9: 82-84.
3. Aswinprakash S, Jagadeesh D, Arulmoli R, Satyanarayana N, Balaji K, Sunitha P. Rare variation of the median nerve in the cubital fossa. Sch Int J Anat Physiol. 2018; 1(4): 112-114.

4. Jnanesh RS. Observation of modes of brachial artery termination in south Indian cadavers. Int J Res Med Sci. 2017; 5 (12):5347-50.

5. Chowdhary R, Ghatak S, Potaliya P. A unique case of accessory brachial artery and its continuation as accessory ulnar artery: A case report. International Journal of Medical and Health Research. 2018; 4(7): 115-117.

6. Gupta R, Aggarwal A, Gupta T, Kaur H, Gaba S, Sahni D. Superficial upper limb vasculature and its surgical implications. Indian J Plast Surg. 2016; 49 (2): 258-260.

7. GJ Romanes. Cunningham's Manual of Practical Anatomy Vol. 1: Upper and Lower Limbs. $15^{\text {th }}$ ed. Oxford University Press Hong Kong. 1986; pp. 67-69.

8. Z Haviarova, HE Falougy, A Killingerova, V Matejcik. Variation of the median nerve course and its clinical importance. Biomed Pap Med Fac Univ Palacky Olomouc Czech Repub. 2009; 153(4):303-306.

9. Chitra, R. Various types of intercommunications between musculocutaneous and median nerve: An analytical study. Ann Indian Acad Neurol. 2007; 10(2): 100-4.

10. Singhal S, Rao VV, Ravindranath R. Variations in brachial plexus and the relationship of median nerve with the axillary artery: a case report. J Brachial Plex Peripher Nerve Inj. 2007; 2: 21.

11. Satyanarayana N, Vishwakarma N, Kumar GP, Guha R, Datta $\mathrm{AK}$ and Sunitha $\mathrm{P}$. Rare variations in the formation of median nerve- embryological basis and clinical significance. Nepal Medical College Journal, 2009b; 11(4): 287-290.

12. Pandey SK, Shukla VK. Anatomical variations of the cords of brachial plexus and the median nerve. Clin Anat. 2007; 20(2):150-6.

13. Budhiraja V, Rastogi R, Asthana AK. Anatomical variations of median nerve formation: embryological and clinical correlation. J Morphol Sci. 2011; 28(4): 283-286.

14. Jakubowicz M, Ratajczak W. Variation in morphology of the biceps brachii and coracobrachialis muscles associated with abnormal course of blood vessels and nerves. Folia Morphol. 2000; 58 (4):255-8.

15. Joshi SD, Joshi SS, Athavale SA. Hitch-hiking fibres of lateral cord of brachial plexus in search of their destination. J Anat Soc India. 2008; 57(1): 26-29.

16. Sudarshan Babu KG, Shubha R, Mekala D, Lalitha C, Jeyanthi $\mathrm{K}$, Relation of median nerve to brachial artery: variations, embryological basis and clinical significance, IOSR Journal of Dental and Medical Sciences (IOSR JDMS). 2013; 9(5): 56-59.

17. Bharti A, Paranjpe VM, Apte MV. Variations in the formation and relation of median nerve, Intl J Anat Res. 2015; 3(3):12981301.

18. Chandrika Teli, Nilesh N Kate, Paarthipan N. High division and variation in brachial artery branching pattern. IOSR Journal of Dental and Medical Sciences (IOSR JDMS). 2013; 3(6): 68-70.

19. Ragiba Zagyapan, Can Pelin, Nuket Mas. Abnormal vascular pattern in the upper limb: original image. Turkiye Klinikleri J Med Sci. 2007; 27: 807-809. 